\title{
Association between Anthropometric Parameters (WC, BMI, WHR) and Type 2 Diabetes in the Adult Yazd Population, Iran
}

\section{Mohammad Hassan Lotfi ${ }^{1}$, Hassan saadati ${ }^{1 *}$ and Majid Afzali $^{3}$}

${ }^{1}$ Associate Professor, Department of Biostatistics \& Epidemiology, Health Faculty, shahid Sadoughi University of Medical Sciences, Islamic Republic of Iran

${ }^{2}$ North Khorasan University of Medical Sciences, Bojnord, Islamic Republic of Iran

\begin{abstract}
Objective: Obesity and particularly abdominal obesity are strongly associated with insulin resistance and type 2 diabetes. The aim of this study was to quantify the association between three anthropometric measurements (body mass index, waist to hip ratio, waist circumference) and type 2 diabetes mellitus in the adult Yazd population, Iran.

Methods: This case-control study conducted among diabetic patients and healthy subjects in the Yazd population, Iran. The study was conducted in a period from December 2012 to May 2013. Studied individuals consisted of 200 patients with Type 2 diabetes and 200 controls without Type 2diabetes. Student t-test was used to assess differences between mean values of two continuous variables. Chi-square analysis was performed to test the differences in proportions of categorical variables between groups and logistic regressions were performed separately for men and women to quantify the association between type 2 diabetes and Body Mass Index (BMI), Waist to Hip Ratio (WHR) and Waist Circumference (WC).
\end{abstract}

Result: $50 \%$ of individuals in each group were female and \%50 males, mean age of the subjects in the case \& control groups were $53.18 \mathrm{yr}$. and $52.60 \mathrm{yr}$. respectively. Mean (SD) WC was $91.62 \mathrm{~cm}(8.9)$ in non-diabetics men and $97.58 \mathrm{~cm}(8.64)$ in diabetics ones, $(p<.001)$. In women, it was $95.5(11.46) \mathrm{cm}$ for non-diabetics and $101.61 \mathrm{~cm}$ (10.26) for diabetics. In the multivariate analysis, Odds ratio [CI95\%] for WC was 3.71 [1.32-10.43] in men and 4.86 [1.14-20.65] in women. Results for BMI and WHR were non-significant in both sexes.

Conclusion: Our study clearly demonstrates that WC is the strongest anthropometric index that associates with type 2 diabetes in both sexes. And this parameter should be used in routine practice for the follow up of patients with type 2 diabetes.

Keywords: Type 2 diabetes; Waist circumference; Waist to hip ratio; Body mass index; Iran

\section{Introduction}

Diabetes Mellitus (DM) is one of the most common chronic diseases in the world and the most challenging health problems of the twenty first century [1]. It is estimated that by the 2030 the number of people with diabetes will increase to more than 366 million, more than twice the number in $2000[2,3]$. Most of these new cases are from developing countries and it seems that the Middle East is among the regions that will have the largest increase in prevalence of diabetes by 2030 [3].

In 2011 it was estimated that 366 million people worldwide had diabetes [4], but its prevalence is increasing rapidly because of increasing age of the population and surge of obesity in many countries including Iran. In Iran, about $10 \%$ of the general population had diabetes mellitus or impaired fasting glucose in 2008 [5]. And in the recent study in Yazd, the result of study showed the prevalence of known diabetes and impaired fasting glucose was $16.3 \%$ and $11.9 \%$ respectively [6].

Type 2 diabetes is a chronic disease characterized by hyperglycemia and dyslipidemia due to underlying insulin resistance. The condition commonly progresses to include micro vascular and macro vascular complications $[7,8]$. Obesity and particularly abdominal obesity are strongly associated with insulin resistance $[9,10]$. Diabetes results from the combination of genetic and environmental factors [11]. There are strong evidences to suggest that modifiable risk factors such as obesity and physical inactivity are the non-genetic determinants of the diabetes $[12,13]$.

The occurrence of rapid and major lifestyle changes in the many countries has increased the prevalence of obesity and other non-communicable disease risk factors such as hypertension and dyslipidemia, which have been reported to be the major etiologic factors the rising incidence of type 2 diabetes around the globe [14].

The Body Mass Index (BMI), defined as the weight in kilograms divided by the height in meters squared, the Waist to Hip Ratio (WHR), and the Waist Circumference (WC) are three main anthropometrics parameters to evaluate body fat and fat repartition in adults. And these parameters have ethnic susceptibility $[15,16]$. Some authors showed that BMI and WHR were predictors of type 2 diabetes outcome [17]. Whereas in other studies, WC was a better predictor of type 2 diabetes mellitus and was more strongly correlated to intra-abdominal fat than WHR $[18,19]$. The aim of this study was to quantify the association between three anthropometric measurements (body mass index, waist to hip ratio, waist circumference) and type 2 diabetes mellitus in the adult Yazd population, Iran.

\section{Materials and Methods}

This was a case-controlstudy, designed to determine the relationship

*Corresponding author: $\mathrm{H}$ Saadati, Department. Of Biostatistics \& Epidemiology Health Faculty, ShahidSadoughi University of Medical Sciences, DaneshjuBlv. Yazd, Islamic Republic of Iran, Tel: 0098-351-6285402; Fax: 0098-351-6245854; E-mail: hasansaadati1391@gmail

Received: May 06, 2014; Accepted: September 25, 2014; Published: October 03, 2014

Citation: Lotfi MH, Saadati H, Afzali M (2014) Association between Anthropometric Parameters (WC, BMI, WHR) and Type 2 Diabetes in the Adult Yazd Population, Iran. J Diabetes Metab 5: 444 doi:10.4172/2155-6156.1000444

Copyright: $\odot 2014$ Lotfi MH, et al. This is an open-access article distributed unde the terms of the Creative Commons Attribution License, which permits unrestricted use, distribution, and reproduction in any medium, provided the original author and source are credited. 
between body mass index, waist to hip ratio, waist circumference and type 2 diabetes mellitus in the adult Yazd population, Iran conducted in a period from December 2012 to May 2013. Yazd city, as reference study population, is located in central of Iran and composed of 980000 populations with unique and homogenous ethnic group. Using appropriate formula and considering proportion of $\mathrm{W} / \mathrm{H}$ ratio of $\% 20$ in general population, confidence interval of $95 \%$, study power of $80 \%$ and at least odds ratio of 1.65 , totally 400 subjects (200 cases and 200 controls) selected by random method. Inclusion criteria for case group were male $\&$ female subjects with age $>30 \mathrm{yr}$. residing in Yazd city and having history of known DM in last 3 years (new cases). Patients were excluded if they had a history of diabetes mellitus type 1 or not living in the Yazd city. Controls were recruited from subjects who referred to the Yazd Central Laboratory For any other reason except for Diabetes and Chronic Diseases. One control was selected and matched on sex and age ( \pm 2 years) using frequency matching. The criteria for controls were not having history of DM or receiving any diabetic medication, not having impaired fasting glucose or type 2 diabetes mellitus following a Fasting blood glucose test. The study was approved by the Medical Ethics Committee of Shahid Sadoughi University of Medical Sciences and Health Services of Yazd. Informed consent was obtained from all participants, which were carried out in accordance with the Declaration of Helsinki. Subjects were interviewed face-to-face by trained interviewers using pretested questionnaires. Information concerning age, gender, family history of diabetes, history of hypertension and dyslipidemia, other information was collected by questionnaire. Anthropometric measures included height, weight; waist and hip circumference were measured according to standard protocols and were recorded. Height was measured in a standing position, without shoes; using a tape stadiometer with a minimum measurement of $1 \mathrm{~cm}$. Weight was measured with each subject wearing light clothing in kilograms by using digital scales $(0.5$ $\mathrm{kg}$ accuracy). Body Mass Index (BMI) was calculated as weight in kilograms divided by height in meters squared. BMI was categorized according to WHO recommendation and obesity was defined as $\mathrm{BMI} \geq 30 \mathrm{~kg} / \mathrm{m}^{2}$ [20]. Waist Circumference (WC) was recorded to the nearest $0.1 \mathrm{~cm}$ at the umbilical level and hip circumference at the maximal level over light clothing, using an unstretched tape meter, without pressure on the body surface. The waist-to-hip ratio (WHR) was calculated as WC divided by hip circumference. We used the criteria of the National Heart, Lung, and Blood Institute (NHLBI) to define the cut-off points for central (or abdominal) obesity. A measure of WC over $88 \mathrm{~cm}$ in women and in $102 \mathrm{~cm}$ in men was considered at risk. Waist hip ratio cut-off points used were $\geq .95$ for men and $\geq .85$ for women [21].

Occupational, commuting, and leisure-time physical activity was assessed using a questionnaire and was categorized in Occupational activity and regular or moderate intensity activity.

Systolic and diastolic blood pressures were measured twice in a seated position in the left arm by digital pressure gauge and the mean value was considered as the subject's blood pressure. Hypertension was defined, according to the JNC7 report ( the report Joint National Committee 7), as a systolic blood pressure $\geq 140 \mathrm{~mm} \mathrm{Hg}$ and/or diastolic blood pressure $\geq 90 \mathrm{~mm} \mathrm{Hg}$, or current use of an antihypertensive medication [22].

Dyslipidemia was defined when one of the following was present: Triglyceride (TG) concentration more than $150 \mathrm{mg} / \mathrm{dl}$ or Cholesterol concentration more than $200 \mathrm{mg} / \mathrm{dl}$ or HDL cholesterol less than 50 $\mathrm{mg} / \mathrm{dl}$ in females and less than $40 \mathrm{mg} / \mathrm{dl}$ in males or LDL more than 100 $\mathrm{mg} / \mathrm{dl}$. This classification was conforming to ATP III (Adult Treatment Panel III) guidelines [23].

\section{Statistical Analysis}

Data analysis was done using the Statistical Package for Social Sciences (SPSS) for Windowsversion 16. The Student t-test was used to assess differences between mean values of two continuous variables. Chi-square analysis was performed to test the differences in proportions of categorical variables between two groups. Unadjusted and adjusted Logistic regression analyses were performed to quantify the association between type 2 diabetes and the explanatory and categorical variables (BMI, WC, WHR). Adjustment was done on all significant covariables in the univariate analysis (among age, family history of diabetes, hypertension, dyslipidemia, physical activity and History of gestational diabetes in women). The analyses were performed for each sex and the Odds Ratios (ORs) of type 2 diabetes and their $95 \%$ confidence intervals (CI95\%) were estimated. The level P value less than 0.05 was considered significant for all tests.

\section{Result}

In this study, 200 patients with type 2 diabetes mellitus (age $>30$ years) and 200 healthy controls (age $>30$ years) were studied. Table 1 shows Characteristics of diabetic and non-diabetic subjects by sex. The mean age of the subjects in the study group (cases) was 53.18 years and that of the subjects in the control group (controls) was 52.60 years. It was

\begin{tabular}{|c|c|c|c|c|c|c|c|c|c|}
\hline & \multicolumn{3}{|c|}{ Total } & \multicolumn{3}{|c|}{ Men } & \multicolumn{3}{|c|}{ Women } \\
\hline & $\begin{array}{c}\text { Cases } \\
\mathrm{N}=200\end{array}$ & $\begin{array}{l}\text { Control } \\
\mathrm{N}=\mathbf{2 0 0}\end{array}$ & $\mathbf{P}$ & $\begin{array}{c}\text { Cases } \\
\mathrm{N}=100\end{array}$ & $\begin{array}{l}\text { Control } \\
N=100\end{array}$ & $\mathbf{P}$ & $\begin{array}{c}\text { Cases } \\
N=100\end{array}$ & $\begin{array}{l}\text { Control } \\
N=100\end{array}$ & $\mathbf{P}$ \\
\hline \multicolumn{10}{|l|}{ Quantitative variable } \\
\hline \multicolumn{10}{|l|}{ Mean \pm SD } \\
\hline Age (year) & $53.18 \pm 9.51$ & $52.60 \pm 9.75$ & 0.54 & $53.20 \pm 9.78$ & $52.82 \pm 10.31$ & 0.79 & $53.17 \pm 9.2$ & $52.39 \pm 9.2$ & 0.55 \\
\hline $\mathrm{BMI}\left(\mathrm{k} / \mathrm{m}^{2}\right)$ & $29.47 \pm 3.95$ & $28.19 \pm 4.67$ & 0.003 & $28.14 \pm 3.28$ & $26.53 \pm 3.23$ & 0.001 & $30.80 \pm 4.12$ & $29.85 \pm 5.27$ & 0.15 \\
\hline WC $(\mathrm{cm})$ & $99.59 \pm 9.68$ & $93.83 \pm 10.47$ & $10^{-4}$ & $97.58 \pm 8.64$ & $91.62 \pm 8.90$ & $10^{-4}$ & $101.61 \pm 10.26$ & $95.05 \pm 11.46$ & $10^{-4}$ \\
\hline WHR & $0.95 \pm 0.07$ & $0.90 \pm 0.06$ & $10^{-4}$ & $0.98 \pm 0.07$ & $0.93 \pm 0.06$ & $10^{-4}$ & $0.93 \pm 0.07$ & $0.88 \pm 0.05$ & $10^{-4}$ \\
\hline \multicolumn{10}{|l|}{ Qualitative variable } \\
\hline \multicolumn{10}{|l|}{$N(\%)$} \\
\hline Family history of diabetes & $145(72.5)$ & $57(28.5)$ & $10^{-4}$ & $70(70)$ & $22(22)$ & $10^{-4}$ & $75(75)$ & $25(25)$ & $10^{-4}$ \\
\hline Hypertension & $117(58.5)$ & $69(34.5)$ & $10^{-4}$ & $57(57)$ & $38(38)$ & 0.007 & $60(60)$ & $31(31)$ & $10^{-4}$ \\
\hline Dyslipidemia & $186(93)$ & $164(82)$ & 0.001 & $90(90)$ & $82(82)$ & 0.10 & $96(96)$ & $82(82)$ & 0.003 \\
\hline Regular physical activity & $125(62.5)$ & $134(67)$ & 0.34 & $61(61)$ & $59(59)$ & 0.77 & $64(64)$ & $75(75)$ & 0.09 \\
\hline
\end{tabular}

Table 1: Characteristics of diabetic and non-diabetic patients by sex. 
Citation: Lotfi MH, Saadati H, Afzali M (2014) Association between Anthropometric Parameters (WC, BMI, WHR) and Type 2 Diabetes in the Adult Yazd Population, Iran. J Diabetes Metab 5: 444 doi:10.4172/2155-6156.1000444

Page 3 of 4

\begin{tabular}{|c|c|c|c|c|c|c|}
\hline & \multicolumn{3}{|c|}{$A$} & \multicolumn{3}{|c|}{$\mathrm{B}$} \\
\hline & OR & $\mathrm{Cl} \% 95$ & $P$ & OR & $\mathrm{Cl} \% 95$ & $P$ \\
\hline \multicolumn{7}{|c|}{ Waist circumference } \\
\hline Men $(n=200)$ & 3.44 & $1.68-7.04$ & 0.001 & 3.71 & $1.32-10.43$ & 0.013 \\
\hline Women $(n=200)$ & 9.12 & $2.63-31.59$ & $10^{-4}$ & 4.86 & $1.14-20.65$ & 0.03 \\
\hline \multicolumn{7}{|l|}{ BMI } \\
\hline Men $(n=200)$ & 2.14 & $1.10-4.15$ & 0.02 & 1.53 & $0.57-4.10$ & 0.39 \\
\hline Women $(n=200)$ & 2.16 & $1.23-3.81$ & 0.007 & 1.42 & $0.69-2.93$ & 0.33 \\
\hline \multicolumn{7}{|l|}{ WHR } \\
\hline Men $(n=200)$ & 2.08 & $1.18-3.66$ & 0.01 & 1.61 & $0.77-3.32$ & 0.19 \\
\hline Women $(n=200)$ & 2.66 & $1.33-5.32$ & 0.005 & 1.50 & $0.61-3.70$ & 0.37 \\
\hline
\end{tabular}

A: The coefficients are unadjusted

$\mathrm{B}$ : The coefficients are adjusted on family history of diabetes and hypertension in men and on family history of diabetes, hypertension, dyslipidemia and History of gestational diabetes in women women.

observed that among diabetics the mean of BMI (29.47), WC (99.59), and WHR (.95) were significantly high compared to non-diabetics $(\mathrm{p}<0.05)$. Whereas no significant difference was noted in relation mean of age $(\mathrm{p}=0.54)$ among diabetics and non-diabetics.

In the group of women, significantly, women with diabetes had a more Family history of diabetes ( $75 \%$ vs. $25 \%, \mathrm{P}=10-4)$, Hypertension (60\% vs. $31 \%, \mathrm{P}=10-4)$ and Dyslipidemia ( $96 \%$ vs. $82 \%, \mathrm{P}=0.003$ ) than women in the other group. Also the Family history of diabetes and Hypertension in men with diabetes were significantly more than men in the other group $(\mathrm{p}<0.05)$. No significant difference was found between cases and controls in both sex for physical activity.

Table 2 shows the results of the logistic regression analysis. In the univariate regression analysis (Table $2 \mathrm{~A}$ ), there were statistically significant relations between type $2 \mathrm{DM}$ and WC, BMI and WHR in both sex. The other variables associated with type $2 \mathrm{DM}$ were: family history of diabetes and hypertension in men and family history of diabetes, hypertension and dyslipidemia in women. However, after adjustment on the other significant factors of the univariate analysis, associations between type $2 \mathrm{DM}$ and BMI and WHR showed no significant in both sex (Table 2B). The regression coefficient for WC was $3.71(95 \%(\mathrm{CI})=1.32-10.43$ and $\mathrm{P}<0.013)$ in men and $4.86(95 \%$ $(\mathrm{CI})=1.14-20.65$ and $\mathrm{P}<0.03)$ in women.

\section{Discussion}

In this case control study performed in 400 subjects aged $>30$ years (200 case and 200 control), we documented significant associations between WC and type 2 diabetes whereas BMI and WHR were not significantly associated with diabetes in both sex. Moreover, our results showed waist circumference was more strongly related to type 2 diabetes in women than the men $(\mathrm{OR}=4.86$ vs. 3.71$)$. Insulin resistance is a major feature of type 2 diabetes, and waist circumference is associated with insulin resistant and type 2 diabetes [24]. Our results clearly demonstrate that WC is the strongest anthropometric index that associates with type 2 diabetes. Consistent with our findings, previous studies also showed that the waist circumference is the best predictor of type 2 diabetes mellitus compared to body mass index, waist/hip ratio and other anthropometric measurements $[18,25]$. There is conflicting evidence on the index of obesity that best reflects diabetic risk. In some studies, waist circumference [19,26,27] and waist-to-hip ratio [28] are better than BMI, in others, BMI is better [29,30] and in others, neither is significantly better [31]. Moreover, both types of obesity (central and overall obesity) may be independent predictors of diabetic risk [32,33]. Differences in data collection methods and not using appropriate statistical methods may be related, to differences in obesity.

In our study group, no relationship was found between diabetes and physical activity which was defined as occupational or moderate activity. Whereas the inverse relationship can be seen in cross-sectional studies between physical activity and type 2 diabetes [34-36]. In this context, prospective studies have shown that physical activity can prevent type 2diabetes [37,38]. Overall, the evidence suggested an important role of physical activity in the prevention of type 2 diabetes. The results from this study showed that waist circumference was strongly associated with type 2 diabetes in both sex. And these parameter which is good measures of abdominal fat, should be used in routine practice for the follow up of patients with type 2 diabetes.

\section{Acknowledgment}

The authors would like to appreciate all subjects, who participated in the present study, the Yazd diabetes research center of Shahid Sadoughi University of medical sciences and Yazd central laboratory.

\section{References}

1. World Health Organization (WHO) (2006) Diabetes mellitus fact sheet no. 312 Geneva.

2. Mehuys E, De Bolle L, Van Bortel L, Annemans L, Van Tongelen I, et al. (2008) Medication use and disease management of type 2 diabetes in Belgium. Pharm World Sci 30: 51-56.

3. Wild S, Roglic G, Green A, Sicree R, King H (2004) Global prevalence of diabetes: estimates for the year 2000 and projections for 2030. Diabetes Care 27: 1047-1053.

4. IDF (2011) Diabetes Atlas, 5th edn. Brussels: International Diabetes Federation

5. Bonakdaran S, Hami M, Hatefi A (2012) The effects of calcitriol on albuminuria in patients with type-2 diabetes mellitus. Saudi J Kidney Dis Transpl 23: 12151220.

6. Lotfi MH, Saadati H2, Afzali M1 (2014) Prevalence of Diabetes in People aged 30 years: The Results of Screen-ing Program of Yazd Province, Iran, in 2012 J Res Health Sci 14: 87-91.

7. Sobel BE, Schneider DJ (2005) Cardiovascular complications in diabetes mellitus. Curr Opin Pharmacol 5: 143-148.

8. Grundy SM, Benjamin IJ, Burke GL, Chait A, Eckel RH, et al. (1999) Diabetes and cardiovascular disease: a statement for healthcare professionals from the American Heart Association. Circulation 100: 1134-1146.

9. Busch CP, Hegele RA (2001) Genetic determinants of type 2 diabetes mellitus Clin Genet 60: 243-254.

10. Dugoujon JM, Guitard E, Sénégas MT, Roth MP, Sanchez A, et al. (2000) Genetic markers of immunoglobulins and diabetes mellitus in the multiracia population of New Caledonia. The CALDIA Study Group. Diabetes Res Clin Pract 47: 209-215 
Citation: Lotfi MH, Saadati H, Afzali M (2014) Association between Anthropometric Parameters (WC, BMI, WHR) and Type 2 Diabetes in the Adult Yazd Population, Iran. J Diabetes Metab 5: 444 doi:10.4172/2155-6156.1000444

11. Tuomilehto J, Lindström J, Eriksson JG, Valle TT, Hämäläinen H, et al. (2001) Prevention of type 2 diabetes mellitus by changes in lifestyle among subjects with impaired glucose tolerance. N Engl J Med 344: 1343-1350.

12. Tuomilehto J, Wolf E (1987) Primary prevention of diabetes mellitus. Diabetes Care 10: 238-248.

13. Manson JE, Rimm EB, Stampfer MJ, Colditz GA, Willett WC, et al. (1991) Physical activity and incidence of non-insulin-dependent diabetes mellitus in women. Lancet 338: 774-778.

14. Zimmet P, Alberti KG, Shaw J (2001) Global and societal implications of the diabetes epidemic. Nature 414: 782-787.

15. Bei-Fan Z; Cooperative Meta-Analysis Group of Working Group on Obesity in China (2002) Predictive values of body mass index and waist circumference for risk factors of certain related diseases in Chinese adults: study on optimal cutoff points of body mass index and waist circumference in Chinese adults. Asia Pac J Clin Nutr 11 Suppl 8: S685-693.

16. Okosun IS, Liao Y, Rotimi CN, Choi S, Cooper RS (2000) Predictive values of waist circumference for dyslipidemia, type 2 diabetes and hypertension in overweight White, Black, and Hispanic American adults. J Clin Epidemiol 53 401-408.

17. Sekikawa A, Eguchi H, Igarashi K, Tominaga M, Abe T, et al. (1999) Waist to hip ratio, body mass index, and glucose intolerance from Funagata populationbased diabetes survey in Japan. Tohoku J Exp Med 189: 11-20.

18. Wang Z, Hoy WE (2004) Body size measurements as predictors of type 2 diabetes in Aboriginal people. Int J Obes Relat Metab Disord 28: 1580-1584.

19. Wei M, Gaskill SP, Haffner SM, Stern MP (1997) Waist Circumference as the Best Predictor of Noninsulin Dependent Diabetes Mellitus (NIDDM) Compared to Body Mass Index, Waist/hip Ratio and Other Anthropometric Measurements in Mexican Americans-A 7-Year Prospective Study. Obesity research 5: p. 1623.

20. World Health Organization, Obesity (2006) Report of WHO consultation on obesity. Geneva: WHO; 1998. Preventing and managing the global epidemic. 1998 Edited by: WHO Geneva 3-5 June 1997

21. Clinical Guidelines on the Identification, Evaluation, and Treatment of Overweight and Obesity in Adults--The Evidence Report. National Institutes of Health. Obes Res 6 Suppl 2: 51S-209S.

22. Chobanian AV, Bakris GL, Black HR, Cushman WC, Green LA et al. (2003) Seventh report of the joint national committee on prevention, detection, evaluation, and treatment of high blood pressure. Hypertension 42: p. 12061252.

23. Third Report of the National Cholesterol Education Program (NCEP) (2002) Expert Panel on Detection, Evaluation, and Treatment of High Blood Cholestero in Adults (Adult Treatment Panel III) final report. Circulation 106: 3143-421.

24. Mamtani M, Kulkarni H, Dyer TD, Almasy L, Mahaney MC, et al. (2013) Wais circumference independently associates with the risk of insulin resistance and type 2 diabetes in mexican american families. PLoS One 8: e59153.
25. Wang Y, Rimm EB, Stampfer MJ, Willett WC, Hu FB (2005) Comparison of abdominal adiposity and overall obesity in predicting risk of type 2 diabetes among men. Am J Clin Nutr 81: 555-563.

26. Mamtani MR, Kulkarni HR (2005) Predictive performance of anthropometric indexes of central obesity for the risk of type 2 diabetes. Arch Med Res 36: 581-589.

27. Rosenthal AD, Jin F, Shu XO, Yang G, Elasy TA, et al. (2004) Body fat distribution and risk of diabetes among Chinese women. Int $\mathrm{J}$ Obes Relat Metab Disord 28: 594-599.

28. Tulloch-Reid MK, Williams DE, Looker HC, Hanson RL, Knowler WC (2003) Do measures of body fat distribution provide information on the risk of type 2 diabetes in addition to measures of general obesity? Comparison of anthropometric predictors of type 2 diabetes in Pima Indians. Diabetes Care 26: $2556-2561$.

29. Chan JM, Rimm EB, Colditz GA, Stampfer MJ, Willett WC (1994) Obesity, fat distribution, and weight gain as risk factors for clinical diabetes in men Diabetes Care 17: 961-969.

30. Sargeant LA, Bennett FI, Forrester TE, Cooper RS, Wilks RJ (2002) Predicting incident diabetes in Jamaica: the role of anthropometry. Obes Res 10: 792-798.

31. Carey VJ, Walters EE, Colditz GA, Solomon CG, Willett WC, et al. (1997) Body fat distribution and risk of non-insulin-dependent diabetes mellitus in women. The Nurses' Health Study. Am J Epidemiol 145: 614-619.

32. Kaye SA, Folsom AR, Sprafka JM, Prineas RJ, Wallace RB (1991) Increased incidence of diabetes mellitus in relation to abdominal adiposity in older women. J Clin Epidemiol 44: 329-334.

33. Baan CA, Stolk RP, Grobbee DE, Witteman JC, Feskens EJ (1999) Physica activity in elderly subjects with impaired glucose tolerance and newly diagnosed diabetes mellitus. Am J Epidemiol 149: 219-227.

34. Defay R, Delcourt C, Ranvier M, Lacroux A, Papoz L (2001) Relationships between physical activity, obesity and diabetes mellitus in a French elderly population: the POLA study. International Journal of Obesity \& Related Metabolic Disorders 25:512-518.

35. Van Dam RM, Schuit AJ, Feskens EJ, Seidell JC, Kromhout D (2002) Physica activity and glucose tolerance in elderly men: the Zutphen Elderly study. Med Sci Sports Exerc 34: 1132-1136.

36. Helmrich SP, Ragland DR, Leung RW, Paffenbarger RS Jr (1991) Physical activity and reduced occurrence of non-insulin-dependent diabetes mellitus. $N$ Engl J Med 325: 147-152.

37. Okada K, Hayashi T, Tsumura K, Suematsu C, Endo G, et al. (2000) Leisuretime physical activity at weekends and the risk of Type 2 diabetes mellitus in Japanese men: the Osaka Health Survey. Diabet Med 17: 53-58.

38. Weinstein AR, Sesso HD, Lee IM, Cook NR, Manson JE, et al. (2004) Relationship of physical activity vs body mass index with type 2 diabetes in women. JAMA 292: 1188-1194. 